\title{
Pemberian Pendidikan Kesehatan untuk Meningkatkan Pengetahuan Keluarga dalam Merawat Lansia Demensia di Puskesmas Pauh, Kota Padang
}

\author{
Rika Sarfika, Feri Fernandes, dan Gentri Mailia \\ Fakultas Keperawatan, Universitas Andalas, Kampus Limau Manis, Padang, 25163. Indonesia \\ E-mail: rikasarfika@nrs.unand.ac.id
}

Keywords: dementia, elderly families, knowledge

\begin{abstract}
Dementia in the elderly tends to increase every year. The elderly affected by dementia requires careful attention and control to prevent things that can endanger the elderly. Many families feel stressed in caring for the elderly, both physical and psychological stress. There are even families who lock up parents at home for reasons of parental safety. This situation can worsen the condition of the elderly who experience dementia. The purpose of these activities is to provide health education to families about how to care for elderly dementia and how to treat it. This activity was carried out at RW 3 Cupak Tangah Pauh, attended by 14 elderly families. The health education method uses a lecture and demonstration approach. A questionnaire consisting of 5 questions was given before and after health education to determine changes in family knowledge. The results of data analysis showed that this activity had increased participants' knowledge about dementia care by 1.14 points (pre-test 3.00 points, post-test 4.14 points). Therefore, we will follow up families through empowering local cadres as a sustainability program.
\end{abstract}

Kata Kunci: demensia, keluarga lansia, pengetahuan

\section{ABSTRAK}

Demensia pada lansia cenderung meningkat setiap tahun. Lansia yang terkena demensia membutuhkan perhatian dan kontrol yang cermat untuk mencegah hal-hal yang dapat membahayakan lansia. Banyak keluarga merasa stres dalam merawat lansia, baik stres fisik maupun psikologis. Bahkan ada keluarga yang mengurung orang tua di rumah karena alasan keamanan orang tua. Situasi ini dapat memperburuk kondisi lansia yang mengalami demensia. Tujuan dari kegiatan ini adalah untuk memberikan pendidikan kesehatan kepada keluarga tentang cara merawat demensia lansia dan cara mengobatinya. Kegiatan ini dilakukan di RW 3 Cupak Tangah Pauh, dihadiri oleh 14 keluarga lansia. Metode pendidikan kesehatan menggunakan pendekatan ceramah dan demonstrasi. Kuisioner yang terdiri dari 5 pertanyaan diberikan sebelum dan sesudah pendidikan kesehatan untuk menentukan perubahan pengetahuan peserta. Hasil analisis data menunjukkan bahwa kegiatan ini meningkatkan pengetahuan peserta tentang perawatan demensia sebesar 1,14 poin (pre-tes 3,00 poin, post-tes 4,14 poin). Sebagai tindak lanjut dari program ini, kami akan melakukan follow-up pada keluarga melalui pemberdayaan kader lokal. 


\section{PENDAHULUAN}

Lanjut usia atau lansia adalah seseorang yang telah mencapai usia 60 (enam puluh) tahun ke atas (Kemenkes RI, 2015). Data dari Kementrian Kesehatan Republik Indonesia (Kemenkes RI) tahun 2018 menyatakan jumlah lansia pada tahun 2017 mencapai 23,66 juta jiwa lansia (9,03\%). Masalah kesehatan jiwa yang sering muncul pada lansia adalah gangguan proses pikir, gangguan perasaan seperti depresi, harga diri rendah, gangguan fisik gangguan prilaku, dan demensia (Azizah, 2011).

Demensia (pikun) adalah kemunduran kognitif yang sedemikian beratnya, sehingga mengganggu aktivitas hidup sehari-hari dan aktivitas sosial (Nugroho, 2008). Data dari World Health Organization (WHO) dan Alzheimer's Disease International Organization melaporkan jumlah total orang dengan demensia di seluruh dunia pada tahun 2015 diperkirakan mencapai 47,5 juta dan sebanyak 22 juta jiwa di antaranya berada di Asia (WHO, 2015). Estimasi jumlah penderita penyakit demensia di Indonesia pada tahun 2013 mencapai satu juta orang, bukannya menurun, tren penderita demensia di Indonesia semakin meningkat setiap tahunnya (Kemenkes, 2016). Sementara itu, hasil rekapitulasi data tahun 2018 yang didapatkan dari Kelurahan Cupak Tangah terdapat sebanyak 540 jiwa lansia.

Berdasarkan studi pendahuluan di RW 3 Kelurahan Cupak Tangah Kecamatan Pauh, ditemukan 4 orang lansia dengan demensia, satu diantaranya dikurung oleh keluarga di ruangan tertutup. Keluarga mengatakan upaya tersebut dilakukan agar lansia tidak keluar rumah dan menghilang karena tidak ingat jalan pulang. Hasil wawancara dengan ketua RW dan kader kesehatan jiwa setempat bahwa selama ini tidak pernah ada penyuluhan atau pendidikan kesehatan tentang demensia. Penyuluhan yang diberikan kepada lansia oleh Puskesmas lebih berfokus pada masalah fisik, seperti hipertensi, reumatik.

Berdasarkan masalah diatas, penulis tertarik untuk memberikan pendidikan kesehatan tentang demensia pada keluarga yang memiliki lansia di RW 3 Kelurahan Cupak Tangah Pauh kota Padang tahun 2019. Tujuan dari kegiatan pengabdian ini adalah meningkatkan pengetahuan dan pemahaman keluarga yang memiliki lansia dalam merawat lansia dengan demensia.

\section{METODE}

Kegiatan ini dilakukan di RW 3 Kelurahan Cupak Tangah Kecamatan Pauh Padang pada tanggal 10 Februari 2019. Metode pelaksanaan kegiatan ini menggunakan pendekatan Community Mental Health Nursing (CMHN) pilar IV yaitu manajemen keperawatan yang bekerja sama dengan puskesmas dan pemberdayaan kader kesehatan dalam mengidentifikasi peserta sesuai kriteria dan menggerakan peserta untuk mengikuti kegiatan. Metode pendidikan kesehatan menggunakan pendekatan ceramah dan demonstrasi dimana peserta diberikan penjelasan mengenai demensia dan melakukan demonstrasi cara merawat lansia demensia. Setelah itu, ada sesi diskusi untuk membicarakan pengalaman peserta dalam merawat lansia.

Kegiatan berlangsung selama 90 menit yang dihadiri oleh peserta sebanyak 14 orang dengan kriteria inklusi keluarga yang memiliki lansia usia 65 tahun ke atas. Kegiatan diawali dengan pengukuran pengetahun peserta tentang demensia (pre-test) dengan mengisi kuesioner evaluasi diri yang terdiri dari 5 item pertanyaan tentang pengertian demensia, penyebab demensia, gejala demensia, penanganan demensia, dan cara merawat lansia demensia. Kegiatan pre-test ini dilakukan selama 15 menit. Kemudian kegiatan dilanjutkan dengan pembukaan kegiatan oleh tokoh masyarakat (ketua RT), pihak puskesmas dan ketua panitia selama 15 menit. Selanjutnya, kegiatan dilanjutkan dengan pemberian pendidikan kesehatan tentang demensia dengan metode ceramah dan demosntrasi yang berlangsung selama 45 menit. Setelah itu, pada sesi akhir dilakukan kembali pengukuran (post-test) yang berlangsung selama 15 menit untuk melihat perubahan pengetahuan keluarga setelah diberikan pendidikan kesehatan tentang demensia. 
Data hasil pre-test dan post-test kemudian di olah menggunakan analisis deskriptif untuk mendapatkan gambaran pengetahuan peserta.

\section{HASIL DAN PEMBAHASAN}

Kegiatan ini adalah berupa pendidikan kesehatan tentang demensia. Peserta yang mengikuti kegiatan sebanyak 14 keluarga yang sesuai dengan kriteria inklusi yaitu keluarga yang memiliki lansia di rumah. Kegiatan juga diikuti oleh kader kesehatan jiwa, tokoh masyarakat (Ketua RT) dan perawat puskesmas penanggung jawab wilayah. Kegiatan berlangsung selama 45 menit yang bertempat di mushola yang terletak di RT 5 RW 3 Kelurahan Cupak Tangah. Bentuk kegiatan dapat dilihat pada gambar 1.

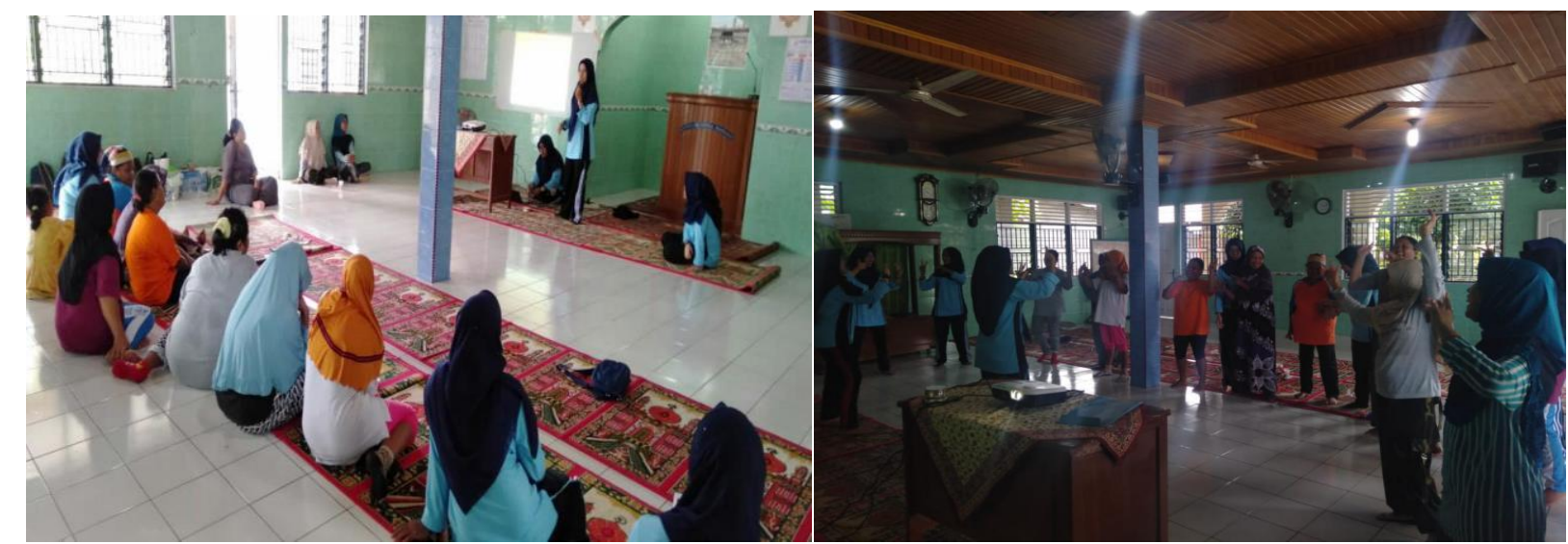

Gambar 1. Peserta sedang memperhatikan penjelasan materi (kiri) dan melakukan teknik relaksasi (kanan)

Hasil kegiatan ditemukan rerata skor pengetahuan keluarga tentang demensia sebelum diberikan pendidikan kesehatan 3,00, dan setelah diberikan pendidikan kesehatan menjadi 4,13. Artinya, terdapat peningkatan rerata skor pengetahuan keluarga tentang demensia sebelum dan setelah diberikan pendidikan kesehatan sebanyak 1,14 point. Hasil analisis data dapat dilihat pada gambar 1.

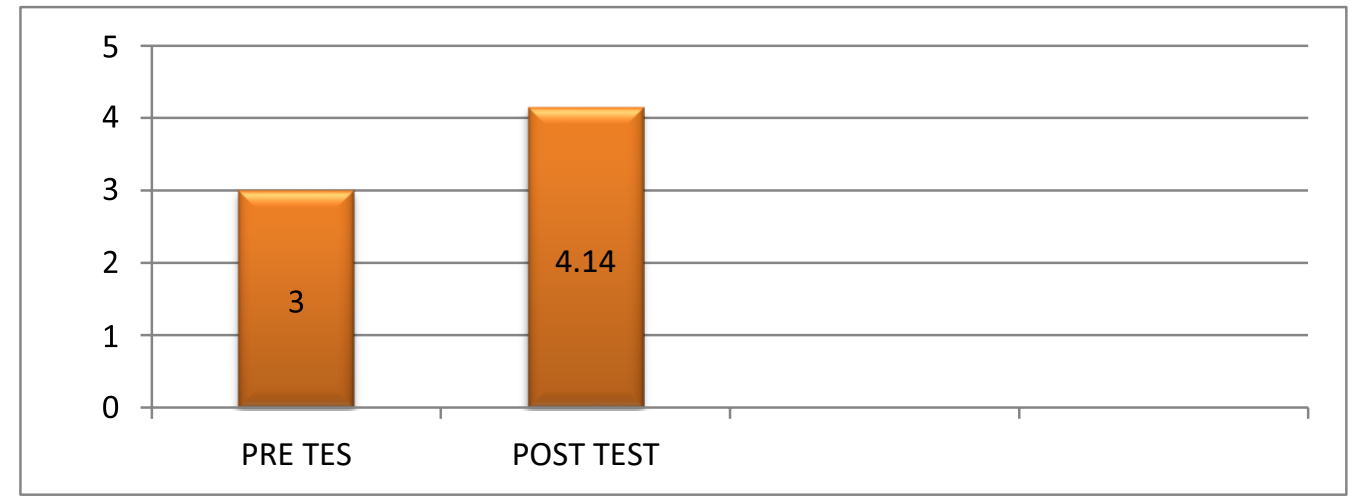

Gambar. 1 Skor Rerata Pengetahuan Keluarga dan Lansia tentang Demensia saat Pre-Test dan Post-Test

Hasil kegiatan ini sejalan dengan penelitian yang dilakukan oleh Husnia (2007) terkait pendidikan kesehatan yang dilakukannya untuk meningkatkan pengetahuan dan sikap lansia tentang demensia di panti Wredha Wening Wardoyo Ungaran, dimana hasilnya menunjukkan adanya peningkatan tingkat pengetahuan lansia tentang demensia setelah diberikan pendidikan kesehatan.

Kegiatan ini dapat meningkatkan pengetahuan keluarga tentang cara merawat lansia demensia diasumsikan karena metode yang digunakan dalam bentuk ceramah dan diselingi dengan demonstrasi dapat memperkuat kemampuan kognitif keluarga. Melalui metode 
demonstrasi, peserta juga diberikan contoh-contoh cara pemecahan masalah berdasarkan pengalaman dan kasus yang pernah terjadi pada peserta. Selain dapat meningkatkan pengetahuan peserta, metode ini juga dapat meningkatkan partisipasi peserta dan mendorong peserta untuk aktif dalam kegiatan pembelajaran. Metode ini juga didukung oleh media yang digunakan yaitu berupa power point yang banyak menyajikan contoh-contoh gambar sehingga keluarga dengan mudah memahami pesan yang disampaikan. Disamping itu, kegiatan ini juga menggunakan leaflet yang berfungsi sebagai bahan bacaan peserta untuk mengenal demensia dan alat peraga yang digunakan ketika melakukan demonstrasi. Sehingga, metode dan media yang digunakan ini membuat peserta antusias untuk belajar dan meningkatkan pengetahuannya tentang demensia.

Sebagai tindak lanjut, tim pengabdi akan melakukan follow-up kepada keluarga melalui bantuan kader kesehatan jiwa setempat. Kegiatan ini tidak menutup kemungkinan akan dilakukan diwilayah lain. Karena kegiatan ini menggunakan metode CMHN dimana kendali kegiatan dipegang oleh perawat yang berada puskesmas, maka tim peneliti akan mensosialisasikan ke puskesmas agar dapat menjadi program dalam kegiatan posyandu lansia.

\section{KESIMPULAN DAN SARAN}

Pendidikan kesehatan tentang demensia pada keluarga yang memiliki lansia dengan menggunakan metode ceramah dan demontrasi dapat meningkatkan pengetahuan keluarga tentang demensia dan cara perawatannya. Maka disarankan pada perawat pemegang program kesehatan jiwa dan lansia di Puskesmas untuk dapat melakukan pendidikan kesehatan secara rutin dan berkelanjutan di wilayah kerja puskesmas Andalas sebagai upaya preventif dalam mengatasi dampak psikologis lanjut dari demensia baik pada keluarga maupun lansia itu sendiri. Selain itu, diharapkan ada upaya promotif juga untuk mengatasi terjadi demensia pada lansia dengan mengajarkan lansia dan keluarga cara pencegahan demensia.

\section{DAFTAR PUSTAKA}

Afnuhazi, R. (2015). Komunikasi terapeutik dalam keperawatan jiwa. Yogyakarta: Gosyen Publishing.

Azizah, Lilik Ma'rifatul (2011). Keperawatan Lanjut Usia. Yogyakarta : Graha Ilmu.

Chan, E. A., Wong, F., Cheung, M. Y., \& Lam, W. (2018). Patients' perceptions of their experiences with nurse-patient communication in oncology settings: A focused ethnographic study. PLoS ONE, 13(6), 1-17. https://doi.org/10.1371/journal.pone.0199183.

Fontaine, K. L (2009). Mental Health Nursing. 6th ed .New Jersey: Pearson Education.

Fortinash, K.M. (2009). Psychiatric Mental Health Nursing. St. Louis Missouri: Mosby-YearBook Inc.

Husnia, Ratna (2007). Pengaruh pendidikan kesehatan terhadap tingkat pengetahuan dan sikap lansia tentang demensia di panti Wredha Wening Wardoyo Ungaran, Surakarta. Tesis Pasca Sarja Keperawatan.

Keliat, B. A, (2011). Keperawatan Kesehatan Jiwa Komunitas. EGC :Jakarta.

Kemenkes RI (2017). Profil Kesehatan Indonesia 2016. http://www.depkes.go.id /resources/download/pusdatin/lain-lain/Data dan Informasi Kesehatan Profil. 
Kourkouta, L., \& Papathanasiou, I. (2014). Communication in Nursing Practice. Materia Socio Medica, 26(1), 65. https://doi.org/10.5455/msm.2014.26.65-67.

Kozier, Barbara.(2004). Fundamentals Of Nursing: concepts, process, and practice (7 th ed.). New Jersey : Pearson.

Leininger, M. \& McFarland, M.R. (2002). Transcultural Nursing: Concepts, theories, Research, and Practice. $3^{\text {th }}$ Edition, USA: Mc-Graw Hill Medical Publishing Division.

Nugroho (2008). Keperawatan Gerontik. Buku Kedokteran EGC: Jakarta.

Omeri, A. \& McFarland, M. (2008). Advances in Contemporary Transcultural Nursing: Transcultural nursing: Pathways of cultural awareness. Vol 8. Issue 1-2. Australia: eContent Management Pty Ltd..

Potter \& Perry. (2009).Fundamental keperawatan (7 th ed.).(vols 2.). dr Adrina \&marina, penerjemah). Jakarta : Salemba Medika.

Riset Kesehatan Dasar. 2013. RISKESDAS 2013. Jakarta: Balitbang Kemenkes RI.

Sheehan, K. A. (2011). Perceived Coercion and the Therapeutic Relationship: ANeglected Association? Psychiatric Services, 62(5), 471. https://doi.org/10.1176/appi.ps.62.5.471

Stuart \& Laraia (2009). Principles and practice of phychiatric nursing. (9th ed). St Louis: Elseviermosby.

Theodoridou, A., Schlatter, F., Ajdacic, V., Rössler, W., \& Jäger, M. (2012). Therapeutic relationship in the context of perceived coercion in a psychiatric population. Psychiatry Research, 200(2-3), 939-944. https://doi.org/10.1016/j.psychres.2012.04.012

Townsend, C.M (2009). Essential of Psychiatric Mental Health Nursing. Ed 6th. Philadelphia : F. A Davis Company. 